\title{
Association of Socioeconomic Factors to Domestic Violence and Murder of Women: The Case of Yucatán, México
}

\author{
Yolanda Oliva Peña \\ “Dr. Hideyo Noguchi” Regional Research Center, The Autonomous University of Yucatan, Mérida, Mexico \\ Email: opena@correo.uady.mx
}

How to cite this paper: Peña, Y. O. (2016). Association of Socioeconomic Factors to Domestic Violence and Murder of Women: The Case of Yucatán, México. Psychology, 7, 19211933.

http://dx.doi.org/10.4236/psych.2016.714175

Received: October 25, 2016

Accepted: December 9, 2016

Published: December 12, 2016

Copyright $\odot 2016$ by author and Scientific Research Publishing Inc. This work is licensed under the Creative Commons Attribution International License (CC BY 4.0).

http://creativecommons.org/licenses/by/4.0/ (c) (i) Open Access

\begin{abstract}
Registration of deaths classified as femicide, is an issue that occupies a breach of law, and that in this matter inconsistencies and absences in the information generated persist and persist in popular culture a strong stigma that various social groups and affected (victims) lead to underreporting of gender violence. Documentary research that conducted to determine the association of geographic areas and social factors related to violence to women occurred in the state of Yucatan during 2004 to 2014. Of the major findings of this study are: there are significant differences in the presence of domestic violence with the economic sector with a value of the test statistic of 13,500 with two degrees of freedom, a significant difference with a $P$-value of 0.001 $(P$-value $<0.05)$ was obtained, and $P$-value $0.000(P$-value $<0.05)$ for the murders of women. Geospatial distribution shows that the municipalities highest number of cases reported are found in large cities, and related to the three sectors of economic activity. Geographical distribution is North, South and East of the state. We conclude that it is required to have a surveillance system for the prevention of gender violence, also provide therapy to both men and women who have lived or have used violence systematically and taught by trained and sensitive to provide such care staff, and thus prevent deaths from gender violence.
\end{abstract}

\section{Keywords}

Gender Violence, Female Homicides, Sector of Economic Activity, Yucatan, Mexico

\section{Introduction}

Gender-based violence as a phenomenon of everyday life has been documented from different fields of knowledge; it has also been recognized as a public health problem. At 
present, the issue of gender violence occupies an important place at the social level: as public, arousing emotions, generating meanings and taking position on incorporated in international discourse in various bodies and institutions, leading to the creation of laws and regulations to address it, including spaces care to victims. National Survey of the dynamics of relationships in households (ENDIREH) (INEGI, 2011) shows that in the country, $16.2 \%$ of married or cohabiting women abused by their partners have suffered aggressions of extreme gravity. This means the existence of a total of $1,785,469$ victims, whose homes such events may create a toxic environment and its effects also pervade their children and close relatives. "Hits" Yucatecan violence... and at home. In the first half of 2,016,000, 27 complaints, 432 more than in the same period last year were presented.

Along with the increase in homicides documented an increase in cases of femicide, while it is true that Yucatan is not placed among the top states for its homicide rate, if in 2013 recorded an unprecedented increase in cases of femicide, mainly perpetrated by people close to women, so that link closely systematic violence of partner or family violence.

So far efforts to understand violence circumscribed gender in various fields, domestic, institutional, educational, political, have given the primary task of characterizing and describing magnitude, intensity and some risk factors, mainly focused on individual profile of the victim or the perpetrator. Few studies that address the problem as sociocultural construct-space and collectively, that in schools is relevant, since it represents the microphysics of global social order.

This situation results in Mexico to put women in a position of vulnerability and risk of death femicide increasing number of geographic areas. In this investigation we start from understanding gender violence as a social construction, which now needs to be analyzed and understood from different perspectives given the influence that social, historical and ideological context exert on it. The identification of violence in couples as a public health problem has been a social, political and ideological progress; however its features have meant a real conceptual and methodological challenge because depending on the theoretical or ideological perspective taken for explanation, prevail individual, structural and cultural factors and, although research on issues of violence has been increasing in recent years, not so with the conceptual and methodological consensus.

The meeting of the expert group of the WHO and the European Economic Commission in 2005 (ECE \& WHO, 2005), noted that is necessary to promote the disaggregation of existing data by sex and gender-sensitize statesmen. Besides this talk about femicide is a difficulty and resistance whenever exhibiting problems of various kinds, representing a fact of systemic violence and impunity, to the "killing of women simply because they are women", is built for direct or indirect State responsibility.

In the Mexican context, in August 2006, the Committee on the Elimination of All Forms of Discrimination against Women issued a series of concluding observations resulting from your visit to our country, among which urged the State to expedite "the approval of the amendment of the Penal Code to typify femicide as a crime". In the 
State of Yucatan it was approved this year, leading to lack of detailed information on cases of femicide and was typified in homicides globally.

There are multiple efforts that have been developed to document the magnitude and frequency of damage gender violence, few efforts to understand and target prevention from a conceptualization of risk, space and social factors, meaning that addresses the this paper Risk and gender violence WHO defines violence: "The intentional use of physical force or power, threatened or actual, against oneself, another person or a group or community, that either results in or has a high likelihood of resulting in injury, death, psychological harm, development or deprivation." The United Nations Conference in Beijing in 1995 defines "violence against women means any act based on gender that results in psychological, sexual, physical damage, including threats of such acts, deprivation of liberty".

Bronfenbrenner (1987) proposed that are diverse causes that give rise to gender violence in the couple and recommends a look that contemplates the interplay of cultural, social and psychological factors. Thus the concept of gender, enrolled in the expression gender violence, refers to the process of social, historical and personal construction (Turinetto and Vicente, 2008) (Corsi, 1999) permeating beliefs, attitudes, feelings, values and behaviors that mark the difference between men and women, substrate necessary for gender violence structural.

Particularly violence against women is multiple dimensions of the problem Velázquez (2003), which are present in forms of silences, omissions, intensions, sayings, models generally Roteed culturally and crack the quality and safety of life same.

Category Risk characterizes a state of complex things, in the sense Luhmman (1992) concept which encompasses several dimensions such as safety, hazard, exposure, including the decision to undergo exposure, conscious or unconscious of the impact of a decision or exposition; also it includes uncertainty about the future, recognizing the danger and the environment, use of the opportunities, accumulation of effects, evaluation of alternatives.

Modern society is characterized as a risk both perceptual level and order and building a social and personal infrastructure, recreated in everyday life. Each social group attributes and acts about the risk from various forms and according to available resources in the sense of power and know-habitus, in the field of gender violence is possible to notice that the social construction of risk are created They are minimizing complex and stigmatize the phenomenon. Is a task for social research, important scale, revealing the resources, opportunities and mechanisms developed in every social and historical context, for them visible and change behaviors mute, immobility amongst other ways to approach the risk of gender-based violence. Thus, the role of research is to denote the differences and risk scenarios of femicide death. Del Valle and Maqueira (2006) propose that is the approach to human rights with a gender perspective as inequalities they experience and live men and women in various fields of everyday life in the symbolic and material, are explained so that the security issues assures us, affects the exercise of autonomy and well-being to preserve life; the au- 
thors recommend that the safety aspect must be observed in an interrelated in all local dimensions possible, group and global, in order to make visible violence spatially and relate the areas of occurrence, interconnected and silenced by the power system dominant.

The social construction of violence is a reality that now needs to be analyzed and understood from different perspectives given the influence that social, historical and ideological context exert on it. Precisely the family is one of the contexts in which violence occurs at an alarming rate, (Doménech \& Iniguez, 2002). According to reports from this author all combinations are possible and the media are responsible for providing evidence of it; parents against children, partners against each other, brothers against brothers, and children against parents; so it look like a modern phenomenon when in fact it is a family as old as the same problem. From the look of this author, family violence should not only be understood as a recent social problem but warrants analysis of a series of socio-historical factors that family violence can be explained and seen also as a social and political problem. In its conclusions it suggests that the discourses of violence are related to specific times and societies that create patterns and different values to define confrontations, situations, interactions and causes. They are always intertwined with other equivalent speeches on race, ethnicity or gender, conforming entirely the defining features of a culture.

The situation of men and women is in changing societies. There is undoubtedly a complex network of social transformations (Carvallo, 2007), and as a result, gender identities are engaged in a process of constant resignifications, also as a result of the feminist movement of the last century that favored the emergence new feminine identities-and also men religious who questioned the patriarchal order, which in turn led, as in all cultural transformation that has represented generic resignification-and follow representando-for men and women face the problem of adjusting to change in various ways and areas (Tolalpa, 2004).

Postmodernism has been instrumental in this process of social transformation and it is precisely this Fernández (2011) warns that sexual dimorphism that seeks to separate rigid and permanent men and women way, male and female, ever cedes more ground, and results in a multidimensional, mobile and contextualized spatial and temporal position and especially taking into account the respective behavior throughout history changes and different societies in relation to what is meant by masculinity and femininity.

However, changes in gender identity not only cause difficulties in men but also women, who placed in contradictory situations and bring them to live among the enjoyment and suffering, but also subject to a conflict between public identity and private identity as a result of a deep internalization of traditional schemes which, in turn, leads to a feeling of guilt for not correspond to gender norms of a given society (Colás, 2007). However, as state Pineda and Otero (2004) it is also necessary to emphasize the need to transform the discourse on masculinities and go beyond mere scapegoating of "man" and recognize the heterogeneity of the group of people grouped under the term "men" and their various experiences and expressions and therefore the standardized culture 
misogynistic and violent.

But undoubtedly, is the female identity which is reacted by new socializations women due to productive and reproductive work live, access to and control of resources, decision-making and new models of parenting, among other factors. Not to mention the private and intimate as love, sexuality and relationships, where the rules are not so clear (Bauman, 2001) ground, something I also agree Beck and Beck-Gernsheim (2003) when they say that in recent years amid a context of confusion young women have more freedom, but they must make up their own rules and behaviors, and especially in the affective domain, vulnerabilities remain to work on the education of women for autonomy in the sense of Lagarde (1997) and sum of positive autonomy, protection of building the relationships with gender violence.

All these social changes have led to changes in gender identity that have caused difficulties in men and women. According to Montesinos and Carrillo (2010), in Mexican society can be seen a process of cultural change that has favored the emergence of new feminine identities, so that, from the sixties, you can find a series of changes in roles and characteristics in women up to the present decade where one could speak of modernity. So that women have to participate simultaneously in the activities of both areas, public and private, with double or even triple working day; they have to deal with the handling of double values, different languages, different demands and conflicting rights (Asakura, 2004). That is why for some approaches, such as postmodern feminism, deconstruction of those identities derived from gender relations (Carvallo, 2006), identities, like the men, should not be unique or permanent sought. Cantera (2004) understanding of violence against women, is facilitated when this phenomenon is in the context of patriarchal culture. For this author patriarchy is a way of sociocultural organization in which male dominance structure social relations on the basis of asymmetrical relations and hierarchical power. In this scenario, the division of male and female roles is established, and the players who are attributed the role and duty to exercise violence and characters that are subject to receive defined. Therefore, patriarchy sees women as the object of control and domination by a male and oppressive social system. It is through the feminist movement that the possibility of questioning the fundamental structures of patriarchy as the traditional family, heterosexuality and male dominance is provided. According Mullender (2000), feminist look a critique of the applications that claim that men become violent due to social pressures (poverty, unemployment, exploitation, poor quality of life), because it defends the fact that they are always the men who assault women, when they are equal social level.

So that different international organizations such as the World Health Organization (WHO, 2003), the United Nations Development Fund for Women (UNIFEM, 2003) and the American Psychological Association (APA, 2002), recommend use of the ecological model to explain gender violence in the couple to identify protective factors against this problem. Since 1988 Heise explains that this theoretical perspective was proposed to organize the results of studies on child abuse and subsequently used for the issue of abuse in the couple. Thus, this author suggests the adoption of the ecological 
structure as a useful tool to compile a lot of existing research and understand gender violence in couples in an inclusive manner.

As Turinetto and Vicente (2008) also points out, gender is a structure that organizes social, family and individual, convenient then make efforts aimed at understanding the social processes of structural generators of gender violence and support public policy eradicate the problem.

Therefore, and there has been difficulty from history, to understand and recognize violence against women. Two basic processes mentioned Corsi (1999) are the invisible and naturalization. The invisibility of male partner violence is directly linked to the absence of conceptual tools to identify it as an object of study.

It is then necessary to generate information to support decision-making for the necessary awareness and therefore the social and cultural change necessary to prevent further damage and deaths from gender violence. I propose to develop the geography of gender violence risk to expose the problem and at the same time exposing inequalities in all areas and in the present case the impact of the comprehensive social and contextual human health. We believe it is necessary entangle the present and the future; Luhmman invites us to incorporate ethics of solving the problems of risk, assuming the analysis of insecurity, danger among other important components of risk, which applied to gender-based violence is of extremely important for the awareness of the population to contribute to the transformation of femicide risk and prevent deaths.

Risk analysis of gender violence in Latin America in the field of health and gender perspective required to work in the search for co-manage most valued "bodies" more protected by laws, rules and regulations of social life as in our contexts "bodies are nested" (Berlanga, 2015) stand as conquerors and conquered-hombres-bodies and bodies to be dominated-mujeres-(Bourdieu, 2009). The intimate femicide and public, including violations related to this assessment while the constant exercise test and reaffirmation of masculinity (Berlanga, 2015).

The purpose of this manuscript is to analyze the association of socioeconomic factors to the facts of domestic violence and murders of women in Yucatan, Mexico, to explore structural aspects that can contribute to the presence of violence, such as geographical distribution and the predominant type of economic activity at the municipal level.

\section{Methodology}

A literature search was conducted to determine the association of geographic areas and social factors related to violence to women occurred in the state of Yucatan during 2004-2014, by reviewing official statistics of the National Institute of Geography and Informatics, the Ministry of Health and other sources of direct information. Domestic violence, sex crimes, killings of women and association with town size and spatial distribution: the variables were analyzed. For statistical analysis the SPSS version 21 program was used: rates were calculated for the association and the Fisher test was applied; also the likelihood of risk of death femicide Reason Proportions test, and Cochran Q laprueba was calculated. For multiple comparisons of factors with cases of domestic vi- 
olence and murder of women. the intensity of the violence is also discussed in two categories: three indicators present and less than three indicators present; the severity of the violence was classified according to two categories total violence, one that presents all the variables analyzed and partial violence municipalities with three or fewer indicators registered and analysis of geospatial distribution of accumulated cases of domestic violence shows and murders of women.

\section{Results}

The national death rate of women in 2013 was 4369 per hundred thousand, the state of 1.24; they include six municipalities with high rates, ranging between 3.85 and 16.50 . The age distribution of deaths this year, shows that $40 \%$ were between 25 and 34 years. Also, $33.33 \%$ of them occurred because of domestic violence, $80 \%$ in this age range. Standardized femicide show $33 \%$ occurring in women between 15 and 24 years and $12 \%$ over 30 to 34 years, which allows point that occurs in relationships from dating to married life and are preventable femicides.

Regarding domestic violence statewide in 2014, 2483 cases were recorded; with a rate of 23.42 per 10,000; municipalities recorded more cases are 1318 Merida, Ticul 606, 248 Valladolid, Panabá and Tekax with 53 each and Buctzotz 51 cases; of those who reported higher rates are Ticul 298.40, Panabácn a rate of 132.19 and Buctzotz with 113.66, followed by Valladolid with 61.81. As for reports of sexual offenses, can be seen over a period of 20 years, there are information gaps in the data recorded; 13 municipalities that historically and some recurrently show, recorded cases of sexual crimes: Buctzotz in 2014; Dzidzantun in 2009; Hunucmá and Uman in 5 years; Izamal, Merida, Progreso, Tekax, Tizimin and Valladolid, for 8 years; Maxcanú 7 years; Motul only in 2010; Ticul in 9 years.

In analyzing the facts of domestic violence by municipality, associated with sector of economic activity according to the classification as a sector 1 Agriculture, Fisheries Sector 2 Mining, Construction, Trade, Sector 3 Services, Tourism, among others shown in Table 1 the distribution shows a predominance of sector 3 and secondly agriculture, fisheries, while the sector 2, registered few cases.

For if there are significant differences in the presence of domestic violence with the economic sector with a value of the test statistic of 13,500 with two degrees of freedom, a significant difference with a $\mathrm{P}$-value of $0.001(P$-value was $<0.05)$, Table 2.

The data of the variables analyzed with the cases in high marginalization is in Table 3 follows:

Table 1. Distribution of cases of domestic violence municipal economic sector.

\begin{tabular}{ccc}
\hline Sector & Absence & Presence \\
\hline 1 & 24 & 13 \\
2 & 33 & 3 \\
3 & 15 & 21 \\
\hline
\end{tabular}

Source by Myself. 
Table 2. Statistical contrast.

\begin{tabular}{cc}
\hline N & 37 \\
Q de Cochran & 15.774 \\
DF & 3 \\
Sig. Asintót. & 0.001 \\
\hline
\end{tabular}

Source by Myself.

Table 3. Frequency of domestic violence cases by sector.

\begin{tabular}{ccc}
\hline Viol/Sector & Absence & Presence \\
\hline Sector 1 & 24 & 13 \\
Sector 2 & 34 & 3 \\
Sector 3 & 16 & 21 \\
Viol. With high marginalization & 24 & 13 \\
\hline
\end{tabular}

Table 4. Multiple pairwise comparisons of domestic violence by sector.

\begin{tabular}{cccccc}
\hline Samples & Statistical test & Typical error & Desv. Statistical test & Significance & Sig. Ady. \\
\hline Sector 2-Sector 1 & 0.250 & 0.136 & 1.837 & 0.066 & 0.199 \\
Sector2-Sector 3 & -0.500 & 0.136 & -3.674 & 0.000 & 0.001 \\
Sector 1-Sector 3 & 0.250 & 0.136 & -1.837 & 0.066 & 0.199 \\
\hline
\end{tabular}

Significance level 0.05 .

Table 5. Test Statistics.

\begin{tabular}{cc}
\hline N & 13 \\
\hline Q de Cochran & 13.000 \\
Df & 1 \\
Sig. asintót & 0.000 \\
\hline
\end{tabular}

Significant differences between sectors adjusted to a level of 0.05 with a $P$-value $<$ 0.05 in sector 2 and 3 are observed (Table 4).

Analysis of domestic violence with social and economic factors: high marginalization and activity sector, no significant differences in pairs for high activity sector and marginalization were found; for the total cases compared to those recorded in highly marginalized a significant difference at a level of 0.05 set with a $P$-value $<0.05$, (Table 5).

Figure 1 shows the distribution of cases of domestic violence according to sector of economic activity predominate in the area of occurrence can be seen; as municipalities highest number of cases reported is found in large cities, and related to the sector 3 of economic activity, geographical distribution is north, south and east of State warns.

The analysis of homicides of women cumulative 2004-2014 notes the following relationship by activity sector, in Table 6, Table 7 . 


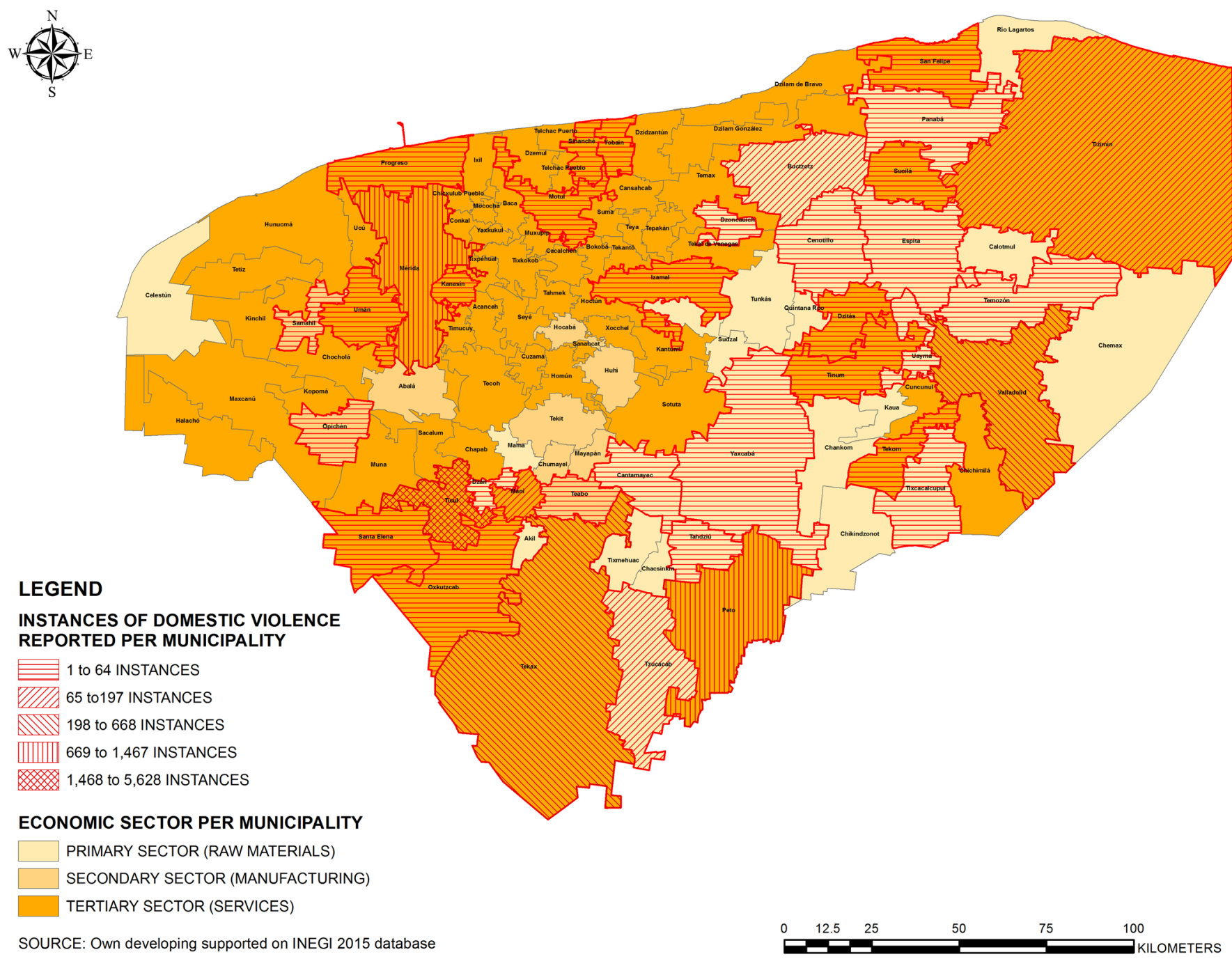

Figure 1. Distribution of cases of domestic violence according to sector of economic activity predominate.

Table 6. Frequency of homicides of women by sector of economic activity. The test statistic Q of Crochran observe the results shown.

\begin{tabular}{rcc}
\hline & \multicolumn{2}{c}{ Valor } \\
\cline { 2 - 3 } & Absence & Presence \\
\hline sector1hommu & 19 & 2 \\
sector2homimu & 21 & 0 \\
sector3homimuj & 2 & 19 \\
\hline
\end{tabular}

Table 7. The test statistic Q of Crochran.

Q de Cochran

Df

Sig. asintót.
19

32.316

2

0.000 
Multiple pairwise comparison shows a significant difference between the sector 2 and 3 , as noted in cases of domestic violence, with a $P$-value $<0.05(P=0.001)$ it can be said with confidence interval $95 \%$ that there are significant differences in the cases of killings of women in the study period, which reveals a direct relationship to economic activities that express a degree of urbanization and therefore fluctuation in employment and wages. The difference is in the couple sector 2 and 3 with an adjusted significance of 0.000 ( $P$-value $<0.05)$. As shown in Table $8 \&$ Table 9.

The analysis of the facts of murders of women in the analysis by sector of activity and high poverty the following results are presented.

It can be stated that there are significant differences between sectors and high marginalization in cases of killings of women, so the test is multiple pairwise comparisons shown in Table 10 is performed

The comparative analysis of homicides shows a significant difference in the murders of women in the economic sector 3 and two; also in highly marginalized municipalities whose main economic activity sector 3; finally found significant differences in the Table 8. Frequency of murders of women by sector and high poverty.

\begin{tabular}{ccc}
\hline & \multicolumn{2}{c}{ Valor } \\
\cline { 2 - 3 } & Ausencia & Presencia \\
\hline Sector 1 hom & 17 & 4 \\
Sector 2 hom & 21 & 0 \\
Sector3 hom & 4 & 17 \\
Marginación & 19 & 2 \\
\hline
\end{tabular}

Table 9. The test statistic $Q$ of Crochran.

\begin{tabular}{cc}
\hline N & 21 \\
Q de Cochran & 32.631 \\
Df. & 3 \\
Sig. asintót & 0.000 \\
\hline
\end{tabular}

Table 10. Contrast peer.

\begin{tabular}{|c|c|c|c|c|c|}
\hline Samples & $\begin{array}{c}\text { Statistical } \\
\text { test }\end{array}$ & $\begin{array}{c}\text { Typical } \\
\text { error }\end{array}$ & $\begin{array}{c}\text { Desv. } \\
\text { Statistical } \\
\text { test }\end{array}$ & Significance & $\begin{array}{l}\text { Sig. } \\
\text { Ady. }\end{array}$ \\
\hline Hom. Sector 2 y Alta marginaciòn & 0.095 & 0.157 & -0.608 & 0.543 & 10.000 \\
\hline Hom. Sector 2 y Sector 1 & 0.190 & 0.157 & 10.215 & 0.224 & 10.000 \\
\hline Hom. Sector 2 y Sector 3 & 0.810 & 0.157 & -50.165 & 0.000 & 0.000 \\
\hline Alta marginación y Hom. Sector 1 & 0.095 & 0.157 & 0.608 & 0.543 & 10.000 \\
\hline Alta marginación y Hom. Sector 3 & 0.714 & 0.157 & 40.557 & 0.000 & 0.000 \\
\hline Hom. Sector 1 y Sector 3 & -0.619 & 0.157 & -30.950 & 0.000 & 0.000 \\
\hline
\end{tabular}




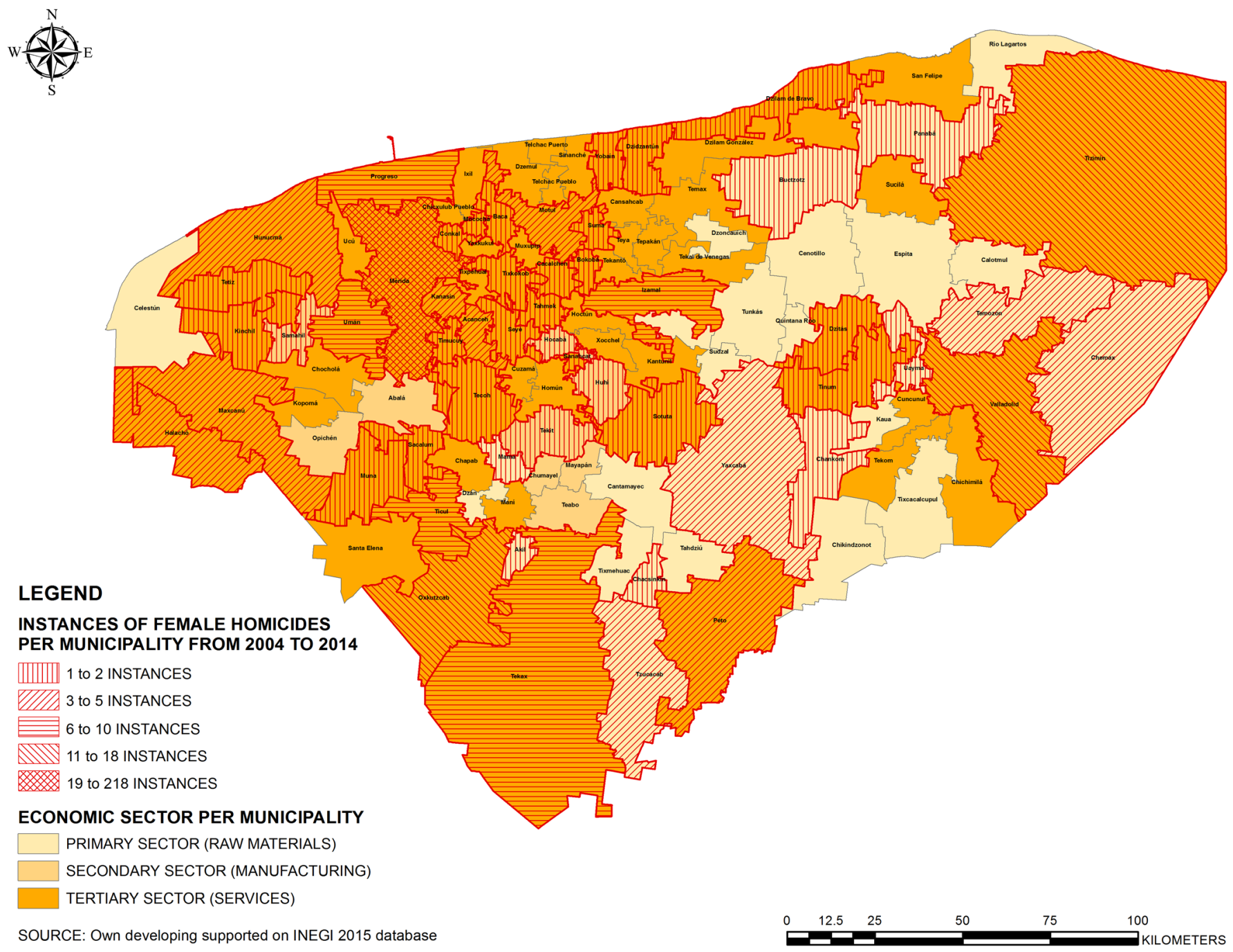

Figure 2. Distribution of cases of killings of women in the state of Yucatan.

killings occurred in the sector of activity 1 and 3, as you can appreciate the distribution below.

Figure 2 is presented shows that the cases of killings of women in the state of Yucatan, the largest number of cases occur in the city of Merida, sector 3, and coincides with the distribution of cases violence in 11 municipalities, and their geographical distribution in terms of the total cases, mainly present in the south and laughing State, Figure 2.

\section{Conclusion}

The sector of economic activity and high poverty proved to be risk factors for domestic violence and murder in the state of Yucatan women.

There remains an absence and possible underreporting of femicide and gender violence requires political will to engage in the process visible, recognition of risk and thus prevent femicide in the State.

A first step was the recent amendment to the regulations for the identification and 
registration as such cases of femicide, which is certainly a turning point to address the problems outlined here. Spatial analysis is an indispensable tool for public policy focused and therefore assesses progress and achievements in eradicating risk for women in contexts of extreme violence. Management of statistical information has been key to catalog the State as low gender violence and minimize the magnitude and trends of feminicide and violence against women, with the presence of large geographic areas of high risk to the lives of women, which requires inter-sectoral public policy for attention.

It is required to have a surveillance system for the prevention of gender violence, also provides therapy to both men and women who have lived or have used violence systematically and taught by trained and sensitive to provide such care staff, and so avoid deaths from gender violence.

\section{References}

Asakura, H. (2004). Are We Overcoming the Gender? Symbolic Order and Feminine Identity. Sociological Studies, 22, 719-743.

Bauman, Z. (2001). The Individualized Society. Madrid: Ediciones Cátedra.

Beck, U., \& Beck-Gernsheim, E. (2003). The Individualization. Institutional Individualism and Its Social and Political Consequences.

Berlanga, M. (2015). Femicide: The Value of Women's Bodies in the Current Latin American Context. Pelican, 1. http://pelicano.ucc.edu.ar/ojs/index.php/pel/article/view/18/11

Bourdieu, P. (2009). Male Dominance. Translated by Jorda, J., 2nd Edition, Spain: Editorial Anagrama, $159 \mathrm{p}$.

Bronfenbrenner, U. (1987). The Ecology of Human Development. Barcelona: Polity Press.

Cantera, L. M. (2004). Beyond Gender. New Approaches of "New" Dimensions and Directions of Intimate Partner Violence. Athenea Digital, 6.

http://redalyc.uaemex.mx/src/inicio/ArtPdfRed.jsp?iCve $=53700636$

Carvallo, P. M. (2006). Gender, Postmodernism and International Relations. The Feminine Identity in the Discourse of the International Organizations. Confines of International Relations and Political Science, 2, 89-100.

Carvallo, P. M. (2007). The Epistemological Turn of Globalization. Confines of International Relations and Political Science, 3, 115-119.

Colás, P. (2007). The Construction of Gender Identity: Theoretical Approaches to Support Research and Educational Intervention. Journal of EducationalResearch, 25, 151-166.

Corsi, J. (1999). Male Intimate Partner Violence. Buenos Aires: Ed.

Del Valle, T., \& Maqueira, V. (2006). The Right to Free and Safe Mobility: Women, Globalization and Human Rights (pp. 245-291). Madrid: Ediciones Chair.

Doménech, M., \& Iniguez, L. (2002). The Social Construction of Violence. Athenea Digital, 2. http://blues.uab.es/athenea/num2/domenech.pdf

Economic Commission for Europe (ECE) and the World Health Organization (WHO) (2005). Violence against Women: Statistical Overview, Challenges and Gaps in Data Collection and Methodology and Approaches to Overcome Them.

Fernández, J. (2011). A Century of Research on Masculinity and Femininity: A Critical Review. Psicothema, 23, 167-172. 
INEGI (2011). ENDIREH.

http://www.inegi.org.mx/est/contenidos/Proyectos/Encuestas/Hogares/especiales/endireh/endi reh2011/default.aspx

Lagarde, M. (1997). Feminist Keys for Women's Empowerment and Autonomy. Nicaragua. Meeting Points.

http://www.caladona.org/grups/uploads/2013/04/claves-feministaspara-el-poderio-y-autonomi a_mlagarde.pdf

Luhmman, N. (1992). Risk Sociology. Guadalajara: University of Guadalajara.

Montesinos, R., \& Carrillo, R. (2010). Feminisms and Masculinities of Cultural Change of End and Beginning of Century. El Cotidiano, 25, 5-14.

Mullender, A. (2000). Domestic Violence: A New Vision of an Old Problem.

Pineda, J., \& Otero, L. (2004). Gender, Intrafamily Violence and Public Intervention in Colombia. Journal of Social Studies, 17, 19-31.

Tolalpa, E. P. (2004). The Routes of Masculinity, by Rafael Montesinos. Sociológica, 19, 277-284.

Turinetto, A. Q., \& Vicente, P. C. (2008). Wife Beaters: Psychological Treatment of Abusers. Madrid: Group 5 Action and Social Management.

Velázquez, S. (2003). Dailyviolence, Genderviolence. Barcelona: Paidós.

World Health Organization (WHO) (2003). World Report on Violence and Health. http://archivos.diputados.gob.mx/Centros_Estudio/ceameg/violencia/siv1/doctos/imsvcomplet o.pdf

Submit or recommend next manuscript to SCIRP and we will provide best service for you:

Accepting pre-submission inquiries through Email, Facebook, LinkedIn, Twitter, etc.

A wide selection of journals (inclusive of 9 subjects, more than 200 journals)

Providing 24-hour high-quality service

User-friendly online submission system

Fair and swift peer-review system

Efficient typesetting and proofreading procedure

Display of the result of downloads and visits, as well as the number of cited articles

Maximum dissemination of your research work

Submit your manuscript at: http://papersubmission.scirp.org/

Or contact psych@scirp.org 